E3S Web of Conferences 1, 22001 (2013)

DOI: $10.1051 / \mathrm{e} 3$ sconf/20130122001

(c) Owned by the authors, published by EDP Sciences, 2013

\title{
A Novel Combination of Methods Developed for Decision Support on Abatement of Mercury in Europe
}

\author{
$\underline{\text { K. Sundseth }}^{1}$ and J. M. Pacyna ${ }^{1,2}$ \\ ${ }^{1}$ NILU - Norwegian Institute for Air Research, Center for Ecology and Economics (CEE), Kjeller, NORWAY, \\ kys@nilu.no \\ ${ }^{2}$ Faculty of chemistry, Gdansk University of Technology, Gdansk, POLAND.
}

\begin{abstract}
There is clear evidence from the global mercury cycle that there is an urgent need for actions to reduce global anthropogenic mercury emissions. A legally- binding global agreement to reduce emissions of mercury is soon in place, meaning that many countries need to take steps to lower their emissions. Identification and assessment of policy options that already are in place as well as setting pollution control objectives and developing effective strategies to meet these objectives, are depending on a decision support tool that allows for identifying current and future environmental problems and to reduce these problems by providing a holistic management approach. Recent scientific advancement allows a more complete picture of the mercury problems and solutions to the problems, which is of outmost interest when it comes to justifying spending resources on the relevant measures. To make sure that resource allocation is favoring human welfare, the economic costs of introducing these measures need to be compared to their economic benefits. The major goal of this study was to provide a novel combination of assessment tools that form a framework for a decision support system towards environmental policy on mercury in Europe. The decision support tool was intended to act as a guideline for policy makers for the purpose of introducing cost- effective abatement of mercury. It was for the EU 27 countries demonstrated that large economic benefits can be achieved globally with reduced mercury emissions in the EU region. The investigated Baseline scenario thus highlighted the importance of full implementation of existing measures and the importance of making further progress in reducing mercury emissions from European sources. Reducing emissions in developing countries may however, be more cost effective, which basically reconfirms the need for a global convention on mercury.
\end{abstract}

Key words: Policy, Mercury, Decision support, Abatement, Costs, Benefits.

\section{Introduction}

Mercury poses in general a global problem. It is persistent, meaning that it does not degrade in the environment. It is mobile because of the volatility of the metal and several of its compounds. It has the ability to cross international borders, predominantly transported in the atmosphere. Finally, it bio-accumulates (particularly in arctic regions), and ultimately becomes a threat to human health via the food chain. It is, therefore, a matter of international concern. The need for cooperative action is recognized in the EU Mercury Strategy (launched in 2005 and reviewed in 2010) and the international actions underway that support and encourage global action on mercury reduction. The EU's Mercury Strategy provided a comprehensive plan incorporating actions addressing mercury pollution both in the EU and globally. It identified a variety of actions to reduce mercury emissions, cut supply, reduce demand and protect against exposure, especially to methylmercury found in fish. The strategy resulted in restrictions on the sale of measuring devices containing mercury, a ban on exports of mercury from the EU (that recently came into force), and new rules on safe storage.

International actions underway that support and encourage global action on mercury reduction is mainly linked to UNEPs (United Nations Environmental Programme) initiative and goal of developing a global convention on mercury which would create a legally binding instrument on mercury prior to 2013. The EU countries are (through the European Commission) leading this process of negotiations, and it is expected implementation of the instrument's targets in the years following 2013. An important phase in deriving a common strategy that the European Commission can take forward to the international negotiations will be 


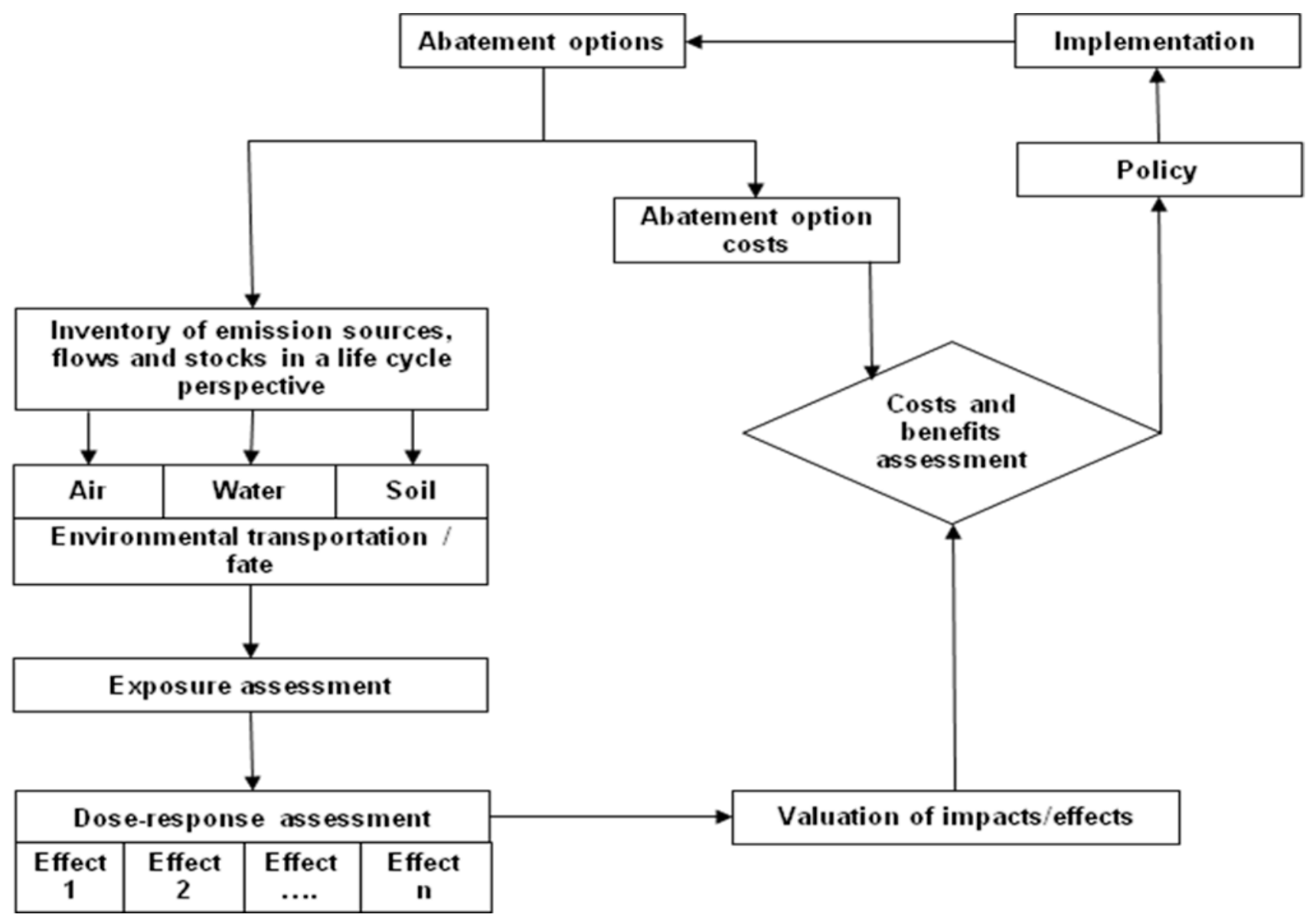

Fig. 1. Structural approach that forms a framework for decision support.

identifying and analyzing their alternative policy options already in place as well as possible future options for reducing mercury emissions. This involves collecting information on effectiveness and economic implications of measures to reduce anthropogenic emissions and to do this within a sound scientific framework. Furthermore, this will allow the EU to take a proactive stance to ensure that it puts in place policy options that represent the best cost- effective measures for the control and reduction of risks associated with mercury. At the same time has advances in scientific based knowledge the last decades lead to a better basis for informed decision making as several studies have been conducted on emission sources and the behavior of mercury in the environment and its environmental and economic consequences associated with its presence.

\section{Materials and Methods}

A novel combination of analytical tools that will help policy makers identify current and future environmental problems of mercury contamination and take decisions on how to reduce these problems by contribution to a proper selection of measures has in this work been demonstrated for the European Union (EU-27) (Sundseth, K., 2012).
The method approaches interdisciplinary including emission estimation in a life cycle perspective, technology assessment, substance flow analysis and dispersion modeling, impact estimation and (socio-) economic evaluation. It provides information on; (i) how control measures affect the emissions, (ii) how the exposure of humans and the environment changes under various control scenarios, (iii) what are the economic values (benefits) of the changes, and (iv) how do these benefits compare to the cost of measures. This work thus contains all the information required to analyze the current situation and to develop cost- effective management approaches on mercury. The structure of the proposed decision support system on reducing mercury emissions in the EU thus reflects a general structure that facilitates a systematic and comprehensive assessment of the relevant costs and benefits of continuing the baseline scenario of mercury pollution compared to the conditions of possible emission restrictions. An overview of the steps which constitute the framework is described in Figure 1 below.

The main Baseline scenario assumptions for the year 2020 (compared to the year 2005) are made on future expectations on economic and social development as well as expectations on fulfilled implementation of the planned policies for the EU 27 region. This includes 
certain measures adopted under the LRTAP conventions, the EU directives, and also agreements to meet the IPCC Kyoto targets on reduction of greenhouse gases that will indirectly cause reduction of mercury emissions.

The alternative 2020 scenario assumes further that all the coal power plants and industrial boilers in the EU implements mercury specific abatement through sorbent injection, - abating almost all the mercury ( $>99 \%)$ in the flue gas.

\section{Results and Discussion}

The investigated Baseline scenario indicates that emissions of mercury as a trace contaminant in fuels and minerals (primary anthropogenic emission sources) are becoming increasingly important to the environmental concentrations in EU compared to emissions from mercury used intentionally e.g. in products (secondary anthropogenic sources). High temperature processes like stationary combustion of coal, associated with energy or heat production in major power plants, small industrial or residential heating units as well as in various industrial processes, were the largest source categories of mercury emissions in 2005 and is also expected to be maintained under the Baseline scenario (Sundseth et al., 2012). Demonstrated results from the decision support system therefore suggests that additional future control strategies in the EU should be targeted industrial sources (which are so far not, or insufficiently, regulated at EU level) and safe treatment of mercury- containing wastes, waste water effluents, as well as residues collected from various combustion processes.

It was for the EU 27 countries demonstrated that large economic benefits can be achieved globally with reduced mercury emissions in the EU region. The investigated Baseline scenario thus highlighted the importance of full implementation of existing measures and the importance of making further progress in reducing mercury emissions from European sources. The cost- benefit analysis, however, indicated that the economic cost of an alternative (additional) technological option for coal combustion in power plants and industrial boilers in the EU exceeds the economic benefits. Reducing emissions in developing countries may be more cost effective, which basically reconfirms the need for a global convention on mercury.

\section{Conclusion}

It was found that national and regional efforts to reduce environmental mercury concentrations need to be complemented, which in turn requires enhanced international coordination on data collection. International processes for harmonizing and exchanging knowledge between different scientific communities, chemicals directives and international programs and conventions, should therefore be promoted. Information can besides be reinforced in the framework of various international programs (i.e. UNEP) and conventions (i.e., UN ECE LRTAP, OSPARCOM, and HELCOM).

The decision support system should be supported by best available scientific advancements and information, including information being made available to the processes in upcoming or existing international agreements such as those under the UNEP negotiations and the UN Economic Commission for Europe (EC) Long-range Transboundary Transport of Air Pollution (LRTAP). Co- operative programmes such as the EMAP (Co-operative Programme for Monitoring and Evaluation of the Long-range Transmission of Air Pollutants in Europe) can regularly provide governments and subsidiary bodies with qualified scientific information to support the development and further evaluation of the international protocols on emission reductions negotiated within the Convention. Such programmes (e.g. the EMEP programme) is carried out in collaboration with a broad network of scientists and national experts that contribute to the systematic collection, analysis and reporting of emission data, measurement data and integrated assessment results.

Transparency in information on production, use, emissions, and costs could be facilitated by harmonizing and exchanging knowledge between different chemicals directives (e.g. the REACH directive) and international conventions, but should also include the industrial sector as well as other relevant stakeholders. Strengthening the links between research, industry and policy communities would improve the availability of existing environmental data for policy implementation purposes.

\section{Acknowledgements}

The authors acknowledge the financial support provided by NILU- Norwegian Institute for Air Research which enabled the successful completion of the study.

\section{References}

REACH, (2008). Guidance on Socio- Economic Analysis Restrictions. Guidance for implementation of REACH. European Chemicals Agency, 2008.

Sundseth, K., (2012). A novel combination of methods developed for decision support on abatement of mercury in Europe. Ph. D. thesis at the Faculty of chemistry, Gdansk University of Technology, Gdansk, POLAND. (Under review).

Sundseth, K., Pacyna, J.M., Pacyna, E.G., Panasiuk, D. (2012). Substance flow analysis of mercury affecting water quality in the European Union. Water air and soil Pollution 223: 429-442. DOI 10.1007/s11270-011-0871-0. 